\title{
Study on the Development of Juvenile Football in Baicheng City Ming $\mathrm{Lu}^{1, \mathrm{a}}$ \\ ${ }^{1}$ Baicheng Normal University, Baicheng, Jilin, 137000 \\ a email
}

\author{
Keywords: Football Teaching, Development Status, Countermeasures
}

\begin{abstract}
This paper discusses the main problems of the development of youth soccer in China from the aspects of system, training idea, training practice, cultural quality cultivation, sociological factors, training mode and coaches, and puts forward some suggestions, that juvenile football should turn to market, adolescent football training to effectively reflect the characteristics of the football project and adapt to the physical and mental development of young people; scientific selection; to improve the young people to improve the development of young people, the cultural quality of football players; fully absorb the advantages of the original training model, especially the school model should be improved; improve the ability and level of youth soccer coaches.
\end{abstract}

\section{Introduction}

Juvenile strong national strong encourage young people to participate in sports, enhance the physical fitness of young people and promote the healthy growth of young people, is to vigorously develop the national sports foundation and foundation, but also with the country and the future of the nation is closely related to the event. To carry out the youth soccer movement, popular youth in the knowledge and skills of football, aimed at enhancing the physical fitness of young people, cultivate young people perseverance, tenacious struggle, unity and cooperation of the competitive sports spirit, cultivate a comprehensive development of young talent for the country's long- It is of great significance to occupy a favorable position in the complex and powerful competition. At the same time, to carry out youth football, is to cultivate the basis of national football reserve talent. Over the past decade, Chinese sports career is booming, only the development of football is not ideal. Chinese men's soccer team continued to slump, hired foreign coach to no avail, still won the World Series competition seat and struggling; and had made the Chinese proud of the Chinese women's football, but also facing the players dating, the dilemma. These Chinese football is difficult to solve the hardships of the refractory, is the moment the young people in China football participation is very small, the lack of football reserve talent reality, in order to improve the country's overall level of football, young people this young, full of vitality and vitality the team is undoubtedly a very important force. It is the basic way to improve the level of football in the whole country by popularizing football knowledge, developing football, exploring and cultivating excellent young soccer players and realizing the expansion of football talent pool in our country. 2015, the State Council promulgated the "China Football Reform and Development of the overall program", from the national strategy of the height, will carry out football, the development of football and the completion of the great rejuvenation of the Chinese nation to achieve the Chinese dream together, pointed out that young people in football Sports, is to achieve the strategic objectives of sports power an important way and inevitable demand, which shows the country for the development of youth football attention. Therefore, in order to young people's own healthy growth, comprehensive development, in order to national football development and the promotion of football level, vigorously carry out youth soccer movement without delay.

\section{The Development Course and Problems of Juvenile Football}

In 1992, China launched the reform of the football management system, the football management mechanism around the country changed, the original planned economic system under the body team as the leading team, all levels of youth amateur sports school as the main competition, training 
management system was broken, replaced is based on professional football club-led, professional football club echelon and football school as the main reserve talent training mode. The new market-oriented model, the proportion of investment from the community increased significantly. However, the model is too much emphasis on efficiency, a lot of quick success, and youth football to carry out the public properties of the opposite, which is not effective young football talent training.

In 2009 the State Sports General Administration and the Ministry of Education jointly issued "on the national youth football campaign notice", a massive campus football officially opened. The State Sports General Administration of the National Games, the provincial Games to reform the system, and as an opportunity to rebuild the youth football talent training mechanism. As of June 2015, the campus football activities have covered 31 provinces, the layout of the school 5084 , the registered number of nearly 200,000, has 2.7 million students to participate in the activities of the campus football. 2015, in order to further revitalize the cause of football, the State Council issued the "China Football Reform and Development Overall Program", from the national development strategy, elaborated the importance of promoting the development of football reform, which promote the development of campus football is particularly critical. "China football reform and development of the overall program," said: "play the role of football education, deepen the reform of school sports, cultivate all-round development of talent, the campus football as the expansion of football population scale, consolidate the foundation of football talent, improve the overall quality of students to promote healthy growth of young people "To promote the cultural learning and the development of football skills and common development"; "to promote the establishment of large and medium primary school campus football team" to promote the development of football and the development of football skills; to improve the normalization of vertical and horizontal through the university, high school, junior high school, primary school four football competition system, so as to promote the growth of young football talent. After these reforms and advances, the popularity of football in the young people showed a significant increase in the trend, the initial formation of the campus football, sports school amateur training and club echelon as the main body of youth football reserve personnel training system.

\section{Problems in the Development of Juvenile Football}

Social environment is not conducive to the development of football. For a long time, Chinese football was surrounded by a variety of negative news: the national team is not satisfactory, the league was gambling, match-fixing, black whistle and other dark clouds, social opinion for football showed a negative attitude of criticism. In addition, in the context of domestic examination-oriented education, "reading is the only way out," the secular concept of deep-rooted, social, family, adolescents own sports indifference is very common. Parents' emphasis on cultural studies and school enrollment indicators is a huge obstacle to the promotion of soccer in the youth population. Moreover, the football emphasizes physical confrontation, high intensity of opponents means that the risk of injury increases, and nowadays young people are the only child in the family, the pearl, parents may play for the young people can play the burden of adolescents, so the Juvenile football has a certain resistance. Even the enlightened parents realized the importance of playing for the young people to improve their physical and comprehensive development, trying to transport the reserve talent for the development of the national football career, but after the professionalization, the professional football club became the only way of youth football talent transmission Related incentives and subsidies have not yet been established, making parents to cultivate young soccer players to bear too much economic burden, its enthusiasm for training talent is undoubtedly a great blow.

Management system is not perfect. The background of the market, Chinese current youth football management system is too dependent on the market, highlighting the economic investment efficiency, which led to quick success, emphasizing the results, rather than concerned about the development of young people, and the development of the nature of the original intention of football Run away. The imperfection of this management system is mainly reflected in the 
following aspects: First, the shortage of funds. Most of the professional clubs are mainly used for first-line adult team competition and training, the use of young people to the echelon is very limited, and some amateur clubs for young players training expenses entirely through the charges to maintain the shortage of funds to restrict youth football main problem. Moreover, the promotion of youth football development function unit is the sports department, and young people mostly for the campus students, these students bear the work of education units and sports functional departments of the disagreement, seriously affected the promotion of youth football development policy The practice and implementation of the school and the lack of professional knowledge and skills of the football coaches, and set up the job is not high, it is difficult to attract the right people to undertake football teaching work.

Training ideas, methods behind, the level of coaches is not high. For a long time, "only performance theory" popular, youth football to carry out too much emphasis on athletic performance, pay attention to form, from reality, in the training can not be the characteristics of football with the physical and mental development characteristics of young people combine to ignore the adolescent football player self-confidence heart and team spirit of cooperation, training concept is not enough science. In addition, Chinese football adhering to the "advanced countries to learn" tradition, Brazil, Spain, Germany, have become the goal of Chinese football learning, learning object of the erratic training of young football training concept often change, sometimes focus on skills, sometimes stressed Physical, without their own cognition and judgment, blindly follow the trend, resulting in the results can only be less effective, low rate of success.

\section{Suggestions on the Development of Juvenile Football}

The development of adolescent football is not individual, school, community, the relevant departments can be completed single-handedly, need all aspects of overall planning, coordinated development. It will be the development of youth soccer into the national government development plan, strengthen the government functions, coordinated by the relevant departments of the government departments to develop the development of youth football is the necessary way. The development of youth soccer can not be separated from the government's support and leadership, can not be separated from the system of protection cannot do without the government's capital investment. In response to the requirements of the overall plan for the development and reform of Chinese football, the strength of various departments such as joint development and reform, education, health, sports, finance and so on, from the macro point of view, clearly defined the specific responsibilities of various departments, combined with Chinese national conditions, the establishment of Chinese characteristics of the youth football development system, co-ordinate the development of youth football to solve the development of many problems encountered.

Learn from the successful experience of football developed countries to cultivate young football talent, establish a people-oriented training concept, dilute the impact of athletic performance, emphasizing the youth football players themselves teamwork, courageously fighting and other excellent quality training, by participating in football to improve their own physical to protect the overall development of individuals, and truly stimulate young people's interest in football, making the cultivation of outstanding football talent to become a natural result rather than the purpose. On the other hand, pay attention to the training of professional football coaches engaged in youth soccer, provide them with the opportunity to study abroad, learn advanced science training methods and standard management measures of football developed countries, and comprehensively enhance the coaching level of coaches. Set up assessment and incentive mechanisms to improve the enthusiasm of young football coaches and social status, to attract more talent to join. To carry out youth soccer, should not be limited to the training of excellent athletes, but also cultivate a comprehensive development, with international vision of the talents. Therefore, in the youth football, in the football skills, physical quality and other professors, training, should not be ignored for young people's moral cultivation, ideological and cultural, logical thinking ability, innovation awareness, communication and communication skills, emotional control, foreign language level And so on the cultivation and improvement, so that young people have developed into a high 
overall quality, can contribute to the community of outstanding international talent.

\section{Conclusion}

The development of youth soccer should integrate the favorable factors of the whole society and make the relevant social departments work together. Because of the institutional changes caused by changes in the training model is inevitable cannot completely deny the original system under the training model, should fully absorb and play the advantages of the original training model, especially the school model should be based on scientific proof and then perfect. The overall ability and level of adolescent football coaches is the prerequisite for the improvement of the level of Chinese football, and the idea of updating and improving the assessment and training system is the key factor.

\section{Acknowledgements}

Project information: Jilin province education science "thirteen five" planning key topic: "Baicheng youth soccer development research", issue number: ZD16054, the project leader: Lu Ming

\section{References}

[1] Li Xipeng. Let the football in the campus "live" up [J]. New curriculum research (late). 2015 (07)

[2] Wang Housheng. Analysis of football rules change on the impact of football [J].Journal of Jiamusi Vocational College. 2017 (05)

[3] Meng Xianghua. Journal of Chifeng University (Natural Science Edition). 2017 (14) (in Chinese)[J]. Journal of Chifeng University (Natural Science Edition)

[4] Yu Zhizhi. A Study on the Realistic Dilemma and Precise Support of Soccer in the Primary and Secondary Schools in Jishou City [J] .Nity Hubei Sports Science and Technology. 2017 (08)

[5] Wang Jie. Chinese campus football to carry out the status quo[J]. College entrance examination. 2017 (24)

[6] Liu Bo. Soccer technology in the operation of the physical principles of analysis[J]. Middle school physics teaching reference. 2017 (14) 